\title{
Feasibility of a Single Contrast Bolus High-Pitch Pulmonary CT Angiography Protocol Followed by Low-Dose Retrospectively ECG- Gated Cardiac CT in Patients with Suspected Pulmonary Embolism Evaluation eines high pitch CT Pulmonalisangiografieprotokolls mit unmittelbar folgender niedrigdosis retrospektiv getriggerter Herz CT Spirale unter Verwendung eines einzigen Kontrastmittelbolus bei Patienten mit Verdacht auf Lungenarterienembolie
}

Authors

Julia Carmen Schäfer ${ }^{1}$, Holger Haubenreisser ${ }^{1}$, Mathias Meyer ${ }^{1}$, Joachim Grüttner ${ }^{2}$, Thomas Walter ${ }^{2}$, Martin Borggrefe ${ }^{3}$, Joseph U. Schoepf ${ }^{4}$, John W. Nance Jr ${ }^{4}$, Stefan O. Schönberg ${ }^{1}$, Thomas Henzler ${ }^{1}$

Affiliations

1 Institute of Clinical Radiology and Nuclear Medicine, University Medical Center Mannheim, Medical Faculty Mannheim, Heidelberg University, Mannheim, Germany

2 Emergency Department, University Medical Center Mannheim, Medical Faculty Mannheim, Heidelberg University, Mannheim, Germany

3 1st Department of Medicine, University Medical Center Mannheim, Medical Faculty Mannheim, Heidelberg University, Mannheim, Germany

4 Radiology, MUSC, Charleston, United States

Key words

pulmonary embolism, right ventricular dysfunction, computed tomography

received 25.03.2017

accepted 21.12.2017

Bibliography

DOI https://doi.org/10.1055/s-0044-100725

Published online: 1.2.2018

Fortschr Röntgenstr 2018; 190: 542-550

(c) Georg Thieme Verlag KG, Stuttgart · New York

ISSN 1438-9029

Correspondence

Herr Dr. Thomas Henzler

Institute of Clinical Radiology and Nuclear Medicine, University Medical Center Mannheim, Heidelberg University, Theodor-Kutzer-Ufer 1 - 3, 68167 Mannheim, Germany

Tel.: ++49/621/3832067

thomas.henzler@me.com

\section{ZUSAMMENFASSUNG}

Einleitung Ziel dieser Studie war die Evaluierung eines high pitch CT Pulmonalis-Angiografie (CTPA) Untersuchungsprotokolls mit unmittelbar folgender niedrigdosis retrospektiv EKG getriggerter Herz CT Spirale unter Verwendung eines einzi- gen Kontrastmittel (KM) Bolus bei Patienten mit Verdacht auf eine akute Lungenembolie (LE) zur detaillierten Analyse der rechtsventrikulären Funktion.

Material und Methoden 62 Patienten (33 weiblich, 65,1 $\pm 17,5$ Jahre) mit Verdacht auf eine akute LE erhielten eine high pitch CTPA gefolgt von einer retrospektiv EKG getriggerten Herz CT Spirale mit reduziertem Röhrenstrom während des gesamten Herzzyklus (4D-cCT). Insgesamt wurde lediglich ein KM Bolus von $80 \mathrm{ml}$ verwendet. Volume CT Dose Index (CTDI vol) und Dosis-Längen-Produkt (DLP) wurden bei allen Patienten registriert und die effektive Dosis berechnet. Zur Beurteilung der Bildqualität wurden an relevanten Stellen Regions-of-Interest (ROIs) plaziert. Anschließend wurden Signal-zu-Rausch Verhältnis (SNR) und Kontrast-zu-Rausch Verhältnis (CNR) berechnet. Die subjektive Bildqualität wurde mittels einer 5-Punkte Likert Skala ermittelt. In der 4D-cCT wurde die Ejektionsfraktion beider Ventrikel (RVEF, LVEF) bestimmt und deren Quotient (RVEF/LVEF) berechnet. Diese Parameter wurden zwischen der LE- und Nicht-LE-Gruppe verglichen.

Ergebnisse Die mittlere effektive Dosis lag bei 4,22 $\pm 2,05 \mathrm{mSv}$. Die höchsten Dichtewerte in der CTPA wurden im Truncus pulmonalis gemessen $(442,01 \pm 187,64)$, in der $4 \mathrm{D}$-cCT in der Aorta descendens $(560,59 \pm 208,81)$. Analog dazu zeigten sich in der CTPA im Truncus pulmonalis (CNR $=12,43 \pm 4,57$; SNR $=15,14 \pm 4,90)$ und in der 4D-cCT in der deszendierenden Aorta (CNR $=10,26 \pm 5,57$; SNR $=10,86$ $\pm 5,17$ ) das höchste CNR und SNR. Die LVEF lag bei $60,73 \%$ $\pm 14,65 \%$, die RVEF bei 44,90\% 9,54\%. Der RVEF/LVEF Quotient lag bei $0,79 \pm 0,29$. Es zeigte sich für keinen Parameter ein signifikanter Unterschied zwischen der LE- und Nicht-LEGruppe.

Schlussfolgerungen Das vorgestellte CT Protokoll ermöglicht die Evaluation der RV Funktion bei Patienten mit akuter LE. Das Ziel künftiger Studien sollte der Vergleich zwischen EKG-synchronisierten und nicht synchronisierten Messungen sein im Hinblick auf einen potentiellen Mehrwert für die Risikostratifizierung von Patienten mit akuter LE. 


\section{Kernaussagen:}

- Die CTPA kann durch den hohen Pitchfaktor so schnell durchgeführt werden, dass ausreichend KM im Herzen verbleibt um dieses für die zusätzliche Herzfunktionsuntersuchung zu verwenden.

- Der Röhrenstrom wird bei der 4D-cCT während des gesamten Herzzyklus reduziert ohne Applikation des vollen Röhrenstroms zu einem bestimmten Zeitpunkt.

- Das durchgeführte Niedrigdosis Herz CT Protokoll erlaubt eine detaillierte Analyse der RV Funktion.

\section{ABSTRACT}

Introduction To prospectively evaluate the feasibility of single contrast bolus high-pitch CT pulmonary angiography (CTPA) subsequently followed by low-dose retrospectively ECG-gated cardiac CT (4D-CCT) in patients with suspected pulmonary embolism (PE) to accurately evaluate right ventricular (RV) function.

Materials and Methods 62 patients (33 female, age 65.1 \pm 17.5 years) underwent high-pitch CTPA examination with $80 \mathrm{cc}$ of iodinated contrast material. $5 \mathrm{~s}$ after the end of the high-pitch CTPA study, a low-dose retrospectively ECG-gated cardiac CT examination was automatically started. The volume CT dose index (CTDI vol) and dose length product (DLP) were recorded in all patients and the effective dose was calculated. For the assessment of image quality, attenuation was measured as Hounsfield units (HUs) within various regions of interest (ROIs). These ROls were used to calculate the signalto-noise ratio (SNR) and contrast-to-noise ratio (CNR). Subjective image quality was assessed using a five-point Likert scale. On 4D-cCT, the ejection fraction of both ventricles (RVEF, LVEF) as well as the ratio of RVEF and LVEF (RVEF/LVEF) was assessed. The statistical difference of all parameters between the PE and non-PE group was calculated.
Results The mean effective radiation dose was $4.22 \pm$ $2.05 \mathrm{mSv}$. Attenuation measurements on CTPA showed the highest attenuation values in the main pulmonary artery (442.01 \pm 187.64$)$. On 4D-cCT attenuation values were highest in the descending aorta $(560.59 \pm 208.81)$. The CNR and SNR values on CTPA were highest within the main pulmonary artery $(C N R=12.43 \pm 4.57 ; S N R=15.14 \pm 4.90)$. On 4D-CCT images, the highest SNR and CNR could be measured in the descending aorta $(C N R=10.26 \pm 5.57$; SNR $=10.86 \pm 5.17)$. The mean LVEF was $60.73 \% \pm 14.65 \%$, and the mean RVEF was $44.90 \% \pm 9.54 \%$. The mean RVEF/LVEF was $0.79 \pm 0.29$. There was no significant difference between the PE and nonPE group for either of the parameters.

Conclusion The investigated combined CTPA and 4D-cCT protocol is feasible using a single contrast bolus and allows the evaluation of RV function in patients with suspected PE. Further studies have to evaluate the additional value of this protocol regarding risk stratification in patients with $\mathrm{PE}$.

\section{Key Points:}

- High-pitch CTPA is fast enough to leave sufficient contrast material within the heart that can be used for an additional low-dose functional cardiac CT examination.

- The tube current of the evaluated 4D-cCT is reduced over the entire cardiac cycle without any full dose peak.

- Low-dose cardiac CT subsequently performed after highpitch CTPA allows for detailed analysis of RV function.

\section{Citation Format}

- Schäfer JC, Haubenreisser H, Meyer M et al. Feasibility of a Single Contrast Bolus High-Pitch Pulmonary CT Angiography Protocol Followed by Low-Dose Retrospectively ECGGated Cardiac CT in Patients with Suspected Pulmonary Embolism. Fortschr Röntgenstr 2018; 190: 542-550

\section{Introduction}

Mortality among patients with non-high-risk pulmonary embolism (PE) varies from $2 \%$ to $8 \%$ [1], depending on possibly existing right ventricular dysfunction (RVD). RVD is the main predictor of short-term mortality in patients with acute PE, leading to secondary hemodynamic instability [2]. Patients with acute RVD require intensive care unit monitoring and might benefit from early thrombolysis or invasive therapies [3]. Therefore, it is essential to assess RV function shortly after the diagnosis of PE. The current ESC guidelines (2014) recommend imaging techniques (computed tomography (CT), echocardiography) and cardiac laboratory biomarkers (Troponin I or T, brain-natriuretic peptide (BNP)) to assess the degree of RV strain. Biomarkers for RVD show a high negative predictive value (NPV) with a low positive predictive value (PPV) [4]. For risk stratification, biomarkers should be combined with CT or echocardiographic measurements [4]. One advantage of echocardiography is the possibility to monitor the clinical course and therapeutic success [5]. On the other hand, echocardiography might not be available 24/7 in every hospital and requires skilled examiners. Within this context, it has been demonstrated that patients with PE who are admitted on weekends have a significantly higher short-term mortality than patients admitted on weekdays [6].

Computed tomography pulmonary angiography (CTPA) signs of RVD, such as RV/left ventricular (LV) ratio $>0.9$, are associated with an adverse outcome [7]. The main advantage of a CT-based assessment of RVD is that the data is already available after the diagnosis of PE. However, CTPA images are not ECG-synchronized and picture the heart at an accidental point during the R-R' interval. This might lead to a possible over-/underestimation of the real RV load.

Several studies tried to solve this problem in the past few years. The potential benefit of additional cardiac ECG-synchronized imaging always weighed against the additive amount of contrast agent and radiation dose $[8,9]$. With the introduction of ultrahigh pitch imaging, CTPA studies can be performed in less than 1 second. These fast acquisition techniques open the field for addi- 
- Table 1 Patient characteristics and preexisting conditions.

- Tab. 1 Patientencharakteristiken und Vorerkrankungen.

\begin{tabular}{|c|c|c|c|c|}
\hline \multicolumn{2}{|l|}{ sex (male/female) } & \multicolumn{3}{|l|}{$28 / 32$} \\
\hline \multicolumn{2}{|l|}{ age (years) } & \multicolumn{3}{|l|}{$64.63 \pm 17.5$} \\
\hline preexisting conditions & $\%$ of all patients & $\begin{array}{l}\text { number of patients } \\
\text { with } P E\end{array}$ & $\begin{array}{l}\text { number of patients } \\
\text { without PE }\end{array}$ & p-value \\
\hline preexisting DVT & 11.7 & 5 & 2 & $0.0004^{*}$ \\
\hline $\mathrm{CHF}$ & 38.3 & 3 & 20 & 1.0000 \\
\hline RHI (without preexisting PE) & 20.0 & 0 & 12 & 0.1823 \\
\hline cardiac decompensation (not PE-related) & 18.3 & 0 & 11 & 0.1888 \\
\hline cardiomyopathy & 8.3 & 1 & 4 & 0.5768 \\
\hline coronary heart disease & 38.3 & 2 & 21 & 0.4598 \\
\hline thrombophilia & 3.3 & 1 & 1 & 0.2797 \\
\hline renal insufficiency & 28.3 & 4 & 13 & 0.2564 \\
\hline diabetes mellitus & 20.0 & 4 & 8 & 0.0689 \\
\hline COPD & 26.7 & 1 & 15 & 0.4215 \\
\hline arrhythmia & 48.3 & 5 & 24 & 0.7270 \\
\hline arterial hypertension & 61.7 & 6 & 31 & 1.0000 \\
\hline nicotine abuse & 23.3 & 1 & 13 & 0.6705 \\
\hline malignoma & 28.3 & 3 & 14 & 0.7035 \\
\hline recent surgery (within 3 months) & 11.7 & 1 & 6 & 1.0000 \\
\hline \multicolumn{5}{|c|}{$\begin{array}{l}\mathrm{PE}=\text { pulmonary embolism, } \mathrm{DVT}=\text { deep vein thrombosis, } \mathrm{CHF}=\text { congestive heart failure, } \mathrm{RHI}=\text { right heart insufficiency, } \mathrm{COPD}=\text { chronic obstructive } \\
\text { pulmonary disease. } \\
\mathrm{PE}=\text { Lungenembolie, } \mathrm{DVT}=\text { Tiefe Venenthrombose, } \mathrm{CHF}=\text { Herzinsuffizienz, } \mathrm{RHI}=\text { Rechtsherzinsuffizienz, COPD = Chronisch obstruktive Lungenerkran- } \\
\text { kung. }\end{array}$} \\
\hline
\end{tabular}

tional subsequent scanning after the CTPA study using the same contrast bolus.

The aim of this study was to evaluate a high-pitch CTPA protocol that is subsequently followed by low-dose ECG-gated cardiac CT with a reduced tube current used for the assessment of RVD.

\section{Materials and Methods}

\section{Patient population}

The HIPAA-compliant study protocol, which is in accordance to the Declaration of Helsinki, was approved by our local ethics committee. Written informed consent was obtained from all patients following a full explanation of the purpose of the study as well as of the risks and discomforts associated with participation.

62 patients (33 female, age $65.1 \pm 17.5$ years) who presented in our emergency department with suspected PE were prospectively included in this study. All patients underwent CT imaging including high-pitch CTPA that was subsequently followed by a lowdose retrospectively ECG-gated functional cardiac examination (4D-cCT).
Age, preexisting conditions and risk factors for deep venous thrombosis or PE were recorded. Exclusion criteria were pregnancy, clinical instability and age < 18y. - Table 1 summarizes the patients' baseline characteristics.

\section{CT protocol}

A high-pitch CTPA examination that was subsequently followed by 4D-cCT was performed in all patients included in the study. Contrast enhancement was achieved by injecting a single contrast bolus of $80 \mathrm{cc}$ (Iomeron 400, Bracco Imaging S.p.A., Milan, Italy) via an antecubital vein access followed by a saline flush of $30 \mathrm{cc}$, both at a flow rate of $4 \mathrm{ml} / \mathrm{s}$. One bolus was used for both parts of the protocol ( $\triangleright$ Fig. 1 ).

55 examinations were performed on a $2^{\text {nd }}$ generation $2 \times 128$ slice dual-source CT (DSCT) system (SOMATOM Definition Flash, Siemens Healthineers, Forchheim, Germany). The remaining 7 examinations were performed on a $3^{\text {rd }}$ generation $2 \times 192$-slice DSCT scanner (SOMATOM Force, Siemens Healthineers, Forchheim, Germany). 


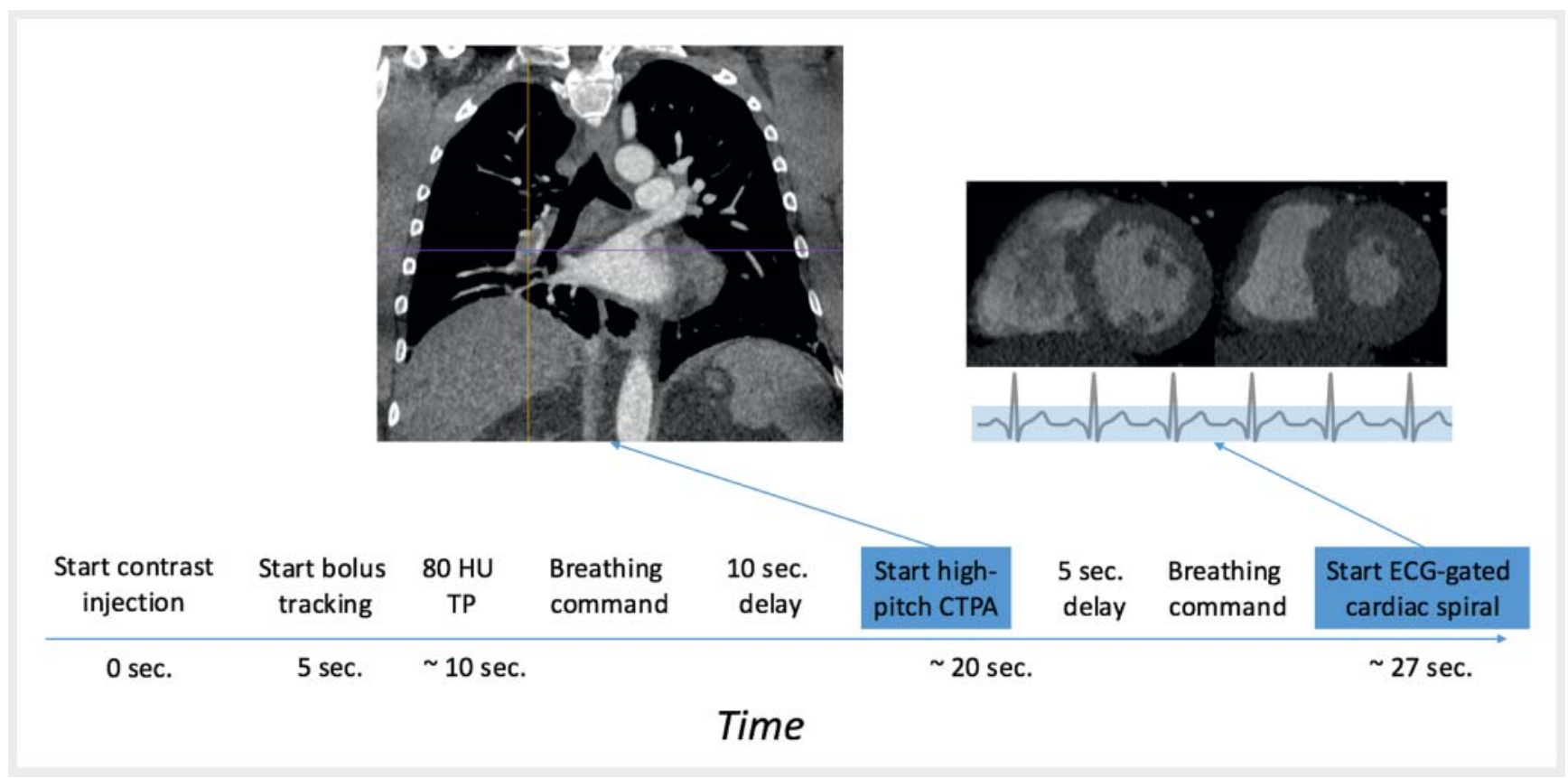

- Fig. 1 Schematic representation of the evaluated dual protocol for diagnosis of pulmonary embolism and functional assessment of cardiac function. Please note that the tube voltage is turned down over the whole cardiac cycle (blue line in ECG) which is different from a standard retrospective cardiac spiral in which the full tube current is usually applied over $40-80 \%$ of the cardiac cycle.

- Abb. 1 Schematische Darstellung des evaluierten dualen CT Protokolls zur Diagnose der Lungenembolie und Auswertung der Herzfunktion. Hinweis: Der Röhrenstrom ist über den gesamten Herzzyklus reduziert (blaue Linie im EKG), was eine Abweichung zu retrospektiven Standard Aufnahmen darstellt, in welchen üblicherweise der volle Röhrenstrom über 40 - 80 \% des Herzzyklus appliziert wird.

\section{CT pulmonary angiography}

The scan parameters for the $2^{\text {nd }}$ generation DSCT system were as follows: $120 \mathrm{kV}$ tube voltage, $80 \mathrm{mAs}$ reference tube current using automated tube current modulation, pitch factor of 3 , collimation of $128 \times 0.6 \mathrm{~mm}$, gantry rotation time of $0.28 \mathrm{~s}$ and reconstructed slice thickness of $1 \mathrm{~mm}$. The scan parameters for the $3^{\text {rd }}$ generation DSCT system were: $70 \mathrm{kV}$ tube voltage, $140 \mathrm{mAs}$ reference tube current using automated tube current modulation, pitch factor of 3 , collimation of $192 \times 0.6 \mathrm{~mm}$, gantry rotation time of $0.25 \mathrm{~s}$ and reconstructed slice thickness of $1 \mathrm{~mm}$.

Bolus tracking was used to define the onset of scanning ( $>80$ $\mathrm{HU}$ in the pulmonary trunk).

\section{D-cCT}

Cardiac ECG-gated scanning started with a delay of $5 \mathrm{~s}$ after the end of the CTPA acquisition and was performed during inspiratory breath-hold. In contrast to standard retrospectively ECG-gated coronary CTA, the tube current of the ECG-gated tube current modulation was reduced by $80 \%$ throughout the entire cardiac cycle without any tube current peak in order to solely evaluate cardiac function with a minimum radiation dose.

The scan parameters for the $2^{\text {nd }}$ generation DSCT system were: $120 \mathrm{kV}$ tube voltage, $50 \mathrm{mAs}$ reference tube current using automated tube current modulation, pitch factor of 0.23 , collimation of $128 \times 0.6 \mathrm{~mm}$, gantry rotation time of $0.28 \mathrm{~s}$ and reconstructed slice thickness of $1.5 \mathrm{~mm}$. The scan parameters for the $3^{\text {rd }}$ generation DSCT system were as follows: $70 \mathrm{kV}$ tube voltage, $20 \mathrm{mAs}$ reference tube current using automated tube current modulation, pitch factor of 0.38 , collimation of $192 \times 0.6 \mathrm{~mm}$, gantry rotation time of $0.25 \mathrm{~s}$ and reconstructed slice thickness of $1.5 \mathrm{~mm}$.

\section{Image post-processing}

For image reconstruction, iterative reconstruction algorithms were used (SAFIRE (Siemens Healthineers, Forchheim, Germany) for the $2^{\text {nd }}$ generation DSCT system with a dedicated soft tissue kernel (I31f) and a lung kernel (I79f) for CTPA and an I26 f kernel for 4D-cCT, ADMIRE (Siemens Healthineers, Forchheim, Germany) for the $3^{\text {rd }}$ generation DSCT system with a Bv36 and Bv40 kernel for CTPA and a Bv40 kernel for 4D-cCT.

The 4D-cCT data was reconstructed in $5 \%$ intervals throughout the cardiac cycle.

\section{Measurements}

CT examinations were analyzed by 2 radiologists ( 7 years and 2 years of CT imaging experience) using Osirix Pro (Version 5.0.2; Aycan, Würzburg, Germany). PE was diagnosed in the case of the presence of at least one filling defect of contrast material in the pulmonary artery tree on the CTPA study.

The volume CT dose index (CTDI vol) and dose length product (DLP) were recorded in all patients. To calculate the effective dose, the DLP was multiplied by a conversion coefficient $(k)$ of $0.014 \mathrm{mSv} /(\mathrm{mGy} \times \mathrm{cm})$ as recommended by the European Guidelines of Multislice Computed Tomography [10]. 
- Table 2 Mean, SD and 95\% confidence interval for effective dose, tube current-exposure time product (mAs), tube potential (kV), volumetric CT dose index (CTDI vol) and dose length product (DLP). Difference between $2^{\text {nd }}$ and $3^{\text {rd }}$ generation DSCT.

- Tab. 2 Mittelwerte, SD und 95\% Konfidenzintervall für die effektive Strahlendosis, Röhrenstromzeitprodukt (mAs), Röhrenspannung (kV), CT Dosis Index (CTDI vol) und Dosis-Längen-Produkt (DLP). Statistischer Unterschied zwischen 2. und 3. Generations-DSCT.

\begin{tabular}{|c|c|c|c|c|}
\hline parameter & $\begin{array}{l}\text { all studies mean } \pm \text { SD } \\
\text { ( } 95 \% \text { confidence interval) }\end{array}$ & $\begin{array}{l}2^{\text {nd }} \text { generation DSCT }(n=53) \\
\text { mean } \pm \text { SD }(95 \% \text { confidence } \\
\text { interval) }\end{array}$ & $\begin{array}{l}3^{\text {rd }} \text { generation DSCT }(n=5) \\
\text { mean } \pm \text { SD }(95 \% \text { confidence } \\
\text { interval) }\end{array}$ & p-value \\
\hline overall effective dose (mSv) & $\begin{array}{l}4.22 \pm 2.05 \\
(3.68-4.76)\end{array}$ & $\begin{array}{l}4.4 \pm 2.00 \\
(3.87-4.98)\end{array}$ & $\begin{array}{l}2.06 \pm 1.24 \\
(0.52-3.60)\end{array}$ & $0.0078^{*}$ \\
\hline effective dose 4D-cCT (mSv) & $\begin{array}{l}1.91 \pm 1.10 \\
(1.62-2.20)\end{array}$ & $\begin{array}{l}1.99 \pm 1.09 \\
(1.69-2.29)\end{array}$ & $\begin{array}{l}1.14 \pm 0.90 \\
(0.02-2.25)\end{array}$ & $0.0403^{*}$ \\
\hline effective dose CTPA (mSv) & $\begin{array}{l}2.18 \pm 1.11 \\
(1.88-2.47)\end{array}$ & $\begin{array}{l}2.29 \pm 1.10 \\
(1.99-2.59)\end{array}$ & $\begin{array}{l}0.99 \pm 0.29 \\
(0.63-1.35)\end{array}$ & $0.0026^{*}$ \\
\hline overall DLP (mGy×cm) & $\begin{array}{l}301.39 \pm 146.71 \\
(262.81-339.97)\end{array}$ & $\begin{array}{l}315.94 \pm 143.13 \\
(276.49-355.40)\end{array}$ & $\begin{array}{l}147.120 \pm 88.52 \\
(37.21-257.03)\end{array}$ & $0.0078^{*}$ \\
\hline DLP 4D-cCT (mGy×cm) & $\begin{array}{l}136.68 \pm 78.40 \\
(116.07-157.30)\end{array}$ & $\begin{array}{l}141.93 \pm 78.07 \\
(120.41-163.44)\end{array}$ & $\begin{array}{l}81.14 \pm 64.25 \\
(1.37-160.91)\end{array}$ & $0.0403 *$ \\
\hline DLP CTPA (mGy×cm) & $\begin{array}{l}155.58 \pm 79.58 \\
(134.66-176.51)\end{array}$ & $\begin{array}{l}163.59 \pm 78.43 \\
(141.97-185.20)\end{array}$ & $\begin{array}{l}70.74 \pm 20.63 \\
(45.12-96.36)\end{array}$ & $0.0026^{*}$ \\
\hline overall CTDI vol (mGy) & $\begin{array}{l}18.23 \pm 8.76 \\
(15.92-20.53)\end{array}$ & $\begin{array}{l}18.96 \pm 8.72 \\
(16.55-21.36)\end{array}$ & $\begin{array}{l}10.52 \pm 4.88 \\
(4.45-16.58)\end{array}$ & $0.0075^{*}$ \\
\hline CTDI vol 4D-cCT (mGy) & $\begin{array}{l}8.15 \pm 4.86 \\
(6.87-9.43)\end{array}$ & $\begin{array}{l}8.43 \pm 4.86 \\
(7.09-9.77)\end{array}$ & $\begin{array}{l}5.14 \pm 4.20 \\
(-0.08-10.36)\end{array}$ & 0.0717 \\
\hline CTDI vol CTPA (mGy) & $\begin{array}{l}4.31 \pm 2.27 \\
(3.72-4.91)\end{array}$ & $\begin{array}{l}4.52 \pm 2.26 \\
(3.90-5.14)\end{array}$ & $\begin{array}{l}2.10 \pm 0.55 \\
(1.41-2.79)\end{array}$ & $0.0056^{*}$ \\
\hline kV 4D-cCT & $\begin{array}{l}74.31 \pm 7.97 \\
(72.21-76.41)\end{array}$ & $\begin{array}{l}73.96 \pm 7.68 \\
(71.85-76.08)\end{array}$ & $\begin{array}{l}78.00 \pm 10.95 \\
(64.40-91.60)\end{array}$ & 0.4041 \\
\hline kV CTPA & $\begin{array}{l}105.17 \pm 16.36 \\
(100.87-109.47)\end{array}$ & $\begin{array}{l}108.11 \pm 13.74 \\
(104.33-111.90)\end{array}$ & $\begin{array}{l}74.00 \pm 5.48 \\
(67.20-80.80)\end{array}$ & $0.0002^{*}$ \\
\hline $\mathrm{mAs} 4 \mathrm{D}-\mathrm{cCT}$ & $\begin{array}{l}165.07 \pm 70.03 \\
(146.66-183.48)\end{array}$ & $\begin{array}{l}168.55 \pm 68.77 \\
(149.59-187.50)\end{array}$ & $\begin{array}{l}128.20 \pm 80.83 \\
(27.84-228.56)\end{array}$ & 0.2212 \\
\hline mAs CTPA & $\begin{array}{l}109.72 \pm 46.47 \\
(97.51-121.94)\end{array}$ & $\begin{array}{l}101.40 \pm 31.91 \\
(92.60-110.19)\end{array}$ & $\begin{array}{l}198.00 \pm 82.91 \\
(95.05-300.95)\end{array}$ & $0.0015^{*}$ \\
\hline
\end{tabular}

$\mathrm{DSCT}=$ dual-source $\mathrm{CT}, \mathrm{N}$ = number of patients, $\mathrm{SD}=$ standard deviation, $4 \mathrm{D}$ - $\mathrm{CCT}=4$-dimensional cardiac computed tomography, $\mathrm{CTPA}=$ computed tomography pulmonary angiography.

DSCT = Dual-Source CT, N = Patientenanzahl, SD = Standardabweichung, 4D-cCT = Herzfunktionsaufnahme, CTPA = CT Pulmonalis-Angiografie .

For the assessment of objective image quality, the attenuation was measured as Hounsfield units (HUs) within various regions of interest (ROIs). On CTPA, one ROI was set in each of the main pulmonary arteries, an apical sub-segmental branch of the right pulmonary artery, a basal sub-segmental branch of the left pulmonary artery and the autochthonous back muscles. On 4D-cCT, one ROI was set in each of the cardiac chambers (right atrium (RA), right ventricle (RV), left atrium (LA) and left ventricle (LV)) as well as the descending aorta and liver. These ROls were used to subsequently calculate the signal-to-noise ratio (SNR) and contrast-to-noise ratio (CNR). The subjective image quality for CTPA and 4D-cCT was assessed by a board-certified radiologist with 10 years of cardiac CT imaging experience. Visualization of the ventricular cavities/pulmonary arteries and image noise were evaluated using a five-point Likert scale (a score of 1 indicated poor visualization/unacceptably high image noise; a score of 2 fair visualization/above-average image noise; a score of 3 moderate visualization/average image noise; a score of 4 good visualization/less than average image noise; and a score of 5 excellent visualization/minimal image noise), artifacts were evaluated using a four-point Likert scale (a score of 1 indicated no artifacts; a score of 2 slight artifacts; a score of 3 definite artifacts; and a score of 4 non-evaluable pulmonary arteries/ventricular cavities).

Ventricular function was assessed on the dynamic 4D-cCT images using a dedicated post-processing workstation (Syngo.Via VA30, Siemens Healthineers, Forchheim, Germany). Images were adjusted to a 2-chamber and 4-chamber view of the heart. Endsystolic and end-diastolic volumes of both the right ventricle (RV) and left ventricle (LV) were measured and used to calculate the ejection fraction (EF). End-systole was defined as the smallest 
- Table 3 Attenuation values (Hounsfield units) on CTPA.

- Tab.3 Dichtewerte (Hounsfield Units) in der CTPA.

\begin{tabular}{|c|c|}
\hline location & $\begin{array}{l}\text { attenuation mean } \pm \text { SD } \\
\text { (95\% confidence interval) }\end{array}$ \\
\hline main pulmonary artery & $\begin{array}{l}442.01 \pm 187.64 \\
(393.54-490.49)\end{array}$ \\
\hline left basal segmental branch & $\begin{array}{l}388.78 \pm 138.09 \\
(353.11-424.46)\end{array}$ \\
\hline right apical segmental branch & $\begin{array}{l}381.88 \pm 141.66 \\
(345.29-418.48)\end{array}$ \\
\hline autochthonous back muscle & $\begin{array}{l}73.38 \pm 12.37 \\
(70.19-76.58)\end{array}$ \\
\hline
\end{tabular}

SD = standard deviation, CTPA = computed tomography pulmonary angiography.

$\mathrm{SD}=$ Standardabweichung, $\mathrm{CTPA}=\mathrm{CT}$ Pulmonalis-Angiografie .

dimension of the ventricular cavity during the cardiac cycle. Correspondingly, end-diastole was defined as the point during cardiac cycle at which the ventricle showed its largest dimension. For volumetric measurements, endocardial contours were drawn automatically. Papillary muscles were included in the ventricular cavity. If necessary, manual corrections of the automatically drawn contours were made.

After the measurement of the EF of both ventricles, the ratio of right ventricular ejection fraction (RVEF) and left ventricular ejection fraction (LVEF) (RVEF/LVEF) was calculated to rule out the influence of gender, age and body surface area on EF.

\section{Statistical analysis}

Statistical analysis was performed using JMP 11.0 (SAS Institute, Cary, NC, USA). Continuous variables are expressed as mean \pm standard deviation (SD), and categorical variables are presented as frequencies with percentages. To prove normal distribution of continuous variables, the Shapiro-Wilk test was used. If data were normally distributed, a two-tailed Student's t-test was used to compare two groups. Otherwise, the Mann-Whitney U-test was used. A p-value $<0.05$ was considered statistically significant.

\section{Results}

\section{PE diagnosis}

A total of 62 CT studies were performed. Two patients were excluded from statistical analysis. One study was of non-diagnostic image quality because of insufficient contrast enhancement of the ventricular cavities - for an automated analysis as well as for manual assessment. The other study was performed in a patient with status post PE (one month ago) and so retrospectively did not fulfill the inclusion criteria. $60 \mathrm{CT}$ studies remained for the data analysis.
- Table 4 Attenuation values (Hounsfield units) on 4D-cCT.

- Tab.4 Dichtewerte (Hounsfield Units) in der Herzfunktionsaufnahme.

\begin{tabular}{|c|c|}
\hline location & $\begin{array}{l}\text { attenuation mean } \pm \text { SD } \\
\text { ( } 95 \% \text { confidence interval) }\end{array}$ \\
\hline RA & $\begin{array}{l}415.50 \pm 263.01 \\
(347.56-483.44)\end{array}$ \\
\hline RV & $\begin{array}{l}432.86 \pm 224.65 \\
(374.83-490.89)\end{array}$ \\
\hline LA & $\begin{array}{l}540.77 \pm 185.58 \\
(492.83-588.71)\end{array}$ \\
\hline LV & $\begin{array}{l}543.64 \pm 188.33 \\
(494.99-592.29)\end{array}$ \\
\hline descending aorta & $\begin{array}{l}560.59 \pm 208.81 \\
(506.65-614.53)\end{array}$ \\
\hline liver & $\begin{array}{l}51.17 \pm 18.37 \\
(46.42-55.91)\end{array}$ \\
\hline \multicolumn{2}{|c|}{$\begin{array}{l}\text { SD = standard deviation, } R A=\text { right atrium, } R V=\text { right ventricle, } \\
\mathrm{LA}=\text { left atrium, } \mathrm{LV}=\text { left ventricle, } 4 \mathrm{D}-\mathrm{cC}=4 \text {-dimensional cardiac } \\
\text { computed tomography } \\
\mathrm{SD}=\text { Standardabweichung, } \mathrm{RA}=\text { rechter Vorhof, } \mathrm{RV}=\text { rechter Ventrikel } \\
\mathrm{LA}=\text { linker Vorhof, } \mathrm{LV}=\text { linker Ventrikel, } 4 \mathrm{D}-\mathrm{cCT}=\text { Herzfunktionsauf- } \\
\text { nahme. }\end{array}$} \\
\hline
\end{tabular}

PE was diagnosed in 9 patients, including 7 central and 2 peripheral PEs.

\section{Radiation dose}

The mean effective dose was $4.22 \mathrm{mSv} \pm 2.05 \mathrm{mSv}(3.72 \mathrm{mSv}-$ $5.29 \mathrm{mSv})$, the mean overall DLP was $301.39 \mathrm{mGy} \times \mathrm{cm} \pm 146.71$ mGy $\times c m(262.81 \mathrm{mGy \times cm}-339.97 \mathrm{mGy} \times \mathrm{cm})$ and the mean overall CTDI vol was 18.23 mGy \pm 8.76 mGy (15.92 mGy 20.53 mGy). For additional dose parameters, see $>$ Table 2.

The chest and heart scan contributed similarly to the overall effective dose. There was a statistically significant difference between the $2^{\text {nd }}$ and $3^{\text {rd }}$ generation DSCT systems for all dose values except for the tube voltage and tube current on $4 \mathrm{D}-\mathrm{cCT}$ ( Table 2 ).

\section{Image quality}

Attenuation measurements on the high-pitch CTPA images ( $\triangleright$ Table 3 ) showed the highest attenuation values in the main pulmonary artery followed by the apical and basal sub-segmental branches.

On the 4D-cCT images, the attenuation values were highest in the descending aorta followed by the left cardiac chambers ( $\vee$ Table 4). The RA and RV had the lowest attenuation values of all cardiac chambers. However, the mean attenuation within both atriums was still above $400 \mathrm{HU}$, which was sufficient for the evaluation of cardiac function.

According to the attenuation values, the contrast-to-noise ratio and signal-to-noise ratio on CTPA showed the highest values 
within the main pulmonary artery, followed by the left basal subsegmental branch. The right apical sub-segmental branch showed the lowest CNR and SNR on CTPA images ( $\triangleright$ Table 5).

On 4D-cCT images, the highest SNR and CNR could be measured in the descending aorta followed by the LV and LA. The lowest SNR and CNR appeared in the RV and RA ( $\vee$ Table 5).

Assessment of the qualitative image quality ( $>$ Table 5 ) revealed slightly better visualization for CTPA than for 4D-cCT $(5(3-5)$ vs. $4(2-5))$ with lower image noise (4 (3-5) vs. 3 $(2-5))$ and equal motion artifacts (both: $1(1-3))$. However, both parts of the protocol showed sufficient image quality for the assessment of pulmonary embolism and the evaluation of right ventricular function. Artifacts were mostly caused by implanted cardioverter defibrillators and pacemakers.

\section{RVEF, LVEF, RVEF/LVEF ratio}

The mean LVEF was $60.73 \% \pm 14.65 \%$ (56.95\% - 64.52\%), and the mean RVEF was $44.90 \% \pm 9.54 \%(42.44 \%-47.36 \%)$. The mean RVEF/LVEF was $0.79 \pm 0.29(0.71-0.86)$. There was no significant difference between the PE and non-PE group for either of the parameters ( $\triangleright$ Table 6 ).

\section{Discussion}

The aim of this study was to evaluate the feasibility of a novel high-pitch CTPA protocol followed by low-dose retrospectively ECG-gated cardiac CT for the assessment of RVD using a single contrast bolus. Our results demonstrate that the protocol is feasible without the use of an additional contrast bolus and allows a detailed analysis of cardiac function. In contrast to a standard retrospectively ECG-gated coronary CT protocol with a high radiation dose, the radiation dose of our protocol was significantly lower since we manually reduced the tube current of the ECG-dependent tube current modulation throughout the whole cardiac cycle.

Echocardiographic findings of RVD have long been reported to be associated with higher mortality rates [11]. Patients with RV hypokinesis on echocardiography showed a doubling of the mortality rate at 14 days compared to patients without RVD [11]. CT measurements of RVD include RV/LV ratios obtained on transverse sections and reconstructed 4 -chamber view. Previous studies have reported a higher accuracy for the RV/LV ratio assessed on 4-chamber view images than on transverse sections compared with echocardiography [7]. RV enlargement on CT has been correlated with a 5-fold increase in the risk of death within 30 days [7]. There are previous studies that also assessed the additional value of ECG-synchronized measurements in patients with acute PE $[8,9]$. Despite showing a potential benefit compared to standard CTPA measurements, the additional radiation dose and contrast agent did prevent a recommendation of ECG-synchronized protocols for routine clinical use. Our study showed a mean effective radiation dose of $4.22 \mathrm{mSv}$ (1.91 mSv for cardiac scanning alone). In contrast, Dogan et al. reported a notably higher effective radiation dose of 3.0-4.2 mSv for cardiac scanning alone [9].
- Table 5 Contrast-to-noise and signal-to-noise ratios for CTPA and 4D-cCT. Median qualitative image quality for CTPA and 4D-cCT.

- Tab.5 Kontrast-zu-Rausch-Verhältnis und Signal-zu-Rausch Verhältnis in der CTPA und 4D-cCT.

\begin{tabular}{|c|c|}
\hline objective image quality & $\begin{array}{l}\text { mean } \pm \text { SD ( } 95 \% \text { confidence } \\
\text { interval) }\end{array}$ \\
\hline CNR RA & $4.80 \pm 3.17(3.98-5.62)$ \\
\hline CNR RV & $6.57 \pm 3.96(5.55-7.59)$ \\
\hline CNR LA & $7.92 \pm 3.30(7.07-8.77)$ \\
\hline CNR LV & $8.66 \pm 3.70(7.71-9.61)$ \\
\hline CNR descending aorta & $10.26 \pm 5.57(8.82-11.70)$ \\
\hline CNR main pulmonary artery & $12.43 \pm 4.57(11.25-13.61)$ \\
\hline CNR right apical segmental branch & $6.11 \pm 7.79(4.09-8.12)$ \\
\hline CNR left basal segmental branch & $7.90 \pm 4.42(6.76-9.05)$ \\
\hline SNR RA & $5.62 \pm 3.35(4.75-6.48)$ \\
\hline SNR RV & $7.54 \pm 4.10(6.48-8.60)$ \\
\hline SNR LA & $8.79 \pm 3.52(7.89-9.70)$ \\
\hline SNR LV & $9.62 \pm 4.04(8.58-10.67)$ \\
\hline SNR descending aorta & $10.86 \pm 5.17(9.53-12.20)$ \\
\hline SNR main pulmonary artery & $15.14 \pm 4.90(13.88-16.41)$ \\
\hline SNR right apical segmental branch & $7.53 \pm 8.91(5.23-9.83)$ \\
\hline SNR left basal segmental branch & $9.87 \pm 5.25(8.52-11.23)$ \\
\hline median qualitative image quality & mean (minimum-maximum) \\
\hline image quality CTPA & $5(3-5)$ \\
\hline image noise CTPA & $4(3-5)$ \\
\hline artifacts CTPA & $1(1-3)$ \\
\hline image quality 4D-cCT & $4(2-5)$ \\
\hline image noise 4D-cCT & $3(2-5)$ \\
\hline artifacts 4D-cCT & $1(1-3)$ \\
\hline \multicolumn{2}{|c|}{$\begin{array}{l}\text { CNR = contrast-to-noise ratio, } S N R=\text { signal-to-noise ratio, } S D=\text { standard } \\
\text { deviation, } R A=\text { right atrium, } R V=\text { right ventricle, } L A=\text { left atrium, } \\
\mathrm{LV}=\text { left ventricle, } 4 \mathrm{D}-\mathrm{cCT}=4 \text {-dimensional cardiac computed tomog- } \\
\text { raphy, } C T P A=\text { computed tomography pulmonary angiography. } \\
\mathrm{CNR}=\text { Kontrast-zu-Rausch Verhältnis, } \mathrm{SNR}=\text { Signal-zu-Rausch Verhältnis, } \\
\mathrm{SD}=\text { Standardabweichung, } R A=\text { rechter Vorhof, } R V=\text { rechter Ventrikel, } \\
\mathrm{LA}=\text { linker Vorhof, LV = linker Ventrikel, } 4 \mathrm{D}-\mathrm{cCT}=\text { Herzfunktionsauf- } \\
\text { nahme, CTPA=CT Pulmonalis-Angiografie. }\end{array}$} \\
\hline
\end{tabular}

Due to the fast image acquisition of high-pitch CTPA in our study, it was possible to use only one $80-\mathrm{ml}$ contrast material bolus for both parts of the protocol. During the functional cardiac examination, contrast medium was mostly concentrated in the left atrium (LA), LV and descending aorta ( $\$$ Table 4). However, there was still sufficient contrast material left within the right cardiac chambers to allow functional RV analysis. The CNR and SNR values for RV and LV were comparable to those published by Takx et al. in a study evaluating a prospectively ECG-triggered coronary CT angiography protocol with an $80 \%$ dose reduction [12]. It has to be pointed out that two different scanner generations with 
- Table 6 Mean values of LVEF, RVEF and RVEF/LVEF for all patients, patients diagnosed with PE and patients without PE. P-values for the statistical difference between PE and non-PE patients.

- Tab. 6 Mittelwerte für LVEF, RVEF und RVEF/LVEF für alle Patienten, Patienten mit LE Diagnose und Patienten, bei denen eine LE ausgeschlossen wurde. P-Werte für den statistischen Unterschied zwischen LE- und Nicht-LE-Patienten.

\begin{tabular}{|c|c|c|c|c|}
\hline parameter & $\begin{array}{l}\text { mean } \pm \text { SD } \\
\text { ( } 95 \% \text { confidence interval) }\end{array}$ & $\begin{array}{l}\text { mean } \pm \text { SD PE } \\
\text { (95\% confidence interval) }\end{array}$ & $\begin{array}{l}\text { mean } \pm \text { SD no PE } \\
\text { (95\% confidence interval) }\end{array}$ & p-value \\
\hline $\operatorname{LVEF}(\%)$ & $\begin{array}{l}60.73 \pm 14.65 \\
(56.95-64.52)\end{array}$ & $\begin{array}{l}62.44 \pm 18.88 \\
(47.94-76.95)\end{array}$ & $\begin{array}{l}60.43 \pm 13.99 \\
(56.50-64.37)\end{array}$ & 0.4311 \\
\hline RVEF (\%) & $\begin{array}{l}44.90 \pm 9.54 \\
(42.44-47.36)\end{array}$ & $\begin{array}{l}42.22 \pm 11.24 \\
(33.59-50.87)\end{array}$ & $\begin{array}{l}45.37 \pm 9.25 \\
(42.77-47.97)\end{array}$ & 0.3653 \\
\hline RVEF/LVEF & $\begin{array}{l}0.79 \pm 0.29 \\
(0.71-0.86)\end{array}$ & $\begin{array}{l}0.74 \pm 0.29 \\
(0.52-0.96)\end{array}$ & $\begin{array}{l}0.80 \pm 0.29 \\
(0.71-0.88)\end{array}$ & 0.3623 \\
\hline
\end{tabular}

$\mathrm{LVEF}=$ left ventricular ejection fraction, RVEF = right ventricular ejection fraction, RVEF/LVEF = ratio of right ventricular ejection fraction and left ventricular ejection fraction, $\mathrm{SD}=$ standard deviation, $\mathrm{PE}=$ pulmonary embolism.

LVEF = linksventrikuläre Ejektionsfraktion, RVEF = rechtsventrikuläre Ejektionsfraktion, RVEF/LVEF = Quotient aus rechtsventrikulärer und linksventrikulärer Ejektionsfraktion, SD = Standardabweichung, $\mathrm{PE}=$ Lungenembolie.

notable differences in radiation dose (and attenuation values) were used in our study. However, images of both scanners were of sufficient image quality to assess right ventricular function. The suggested protocol is also transferable to other high-end CT systems, even non-DSCT systems that allow rapid thoracic CT of less than $2 \mathrm{~s}$ (e. g. CT systems with larger detector coverage instead of high-pitch imaging).

Using the remaining contrast medium for additional cardiac scanning allowed us to evaluate not only RV but also LV function.

In our study, we did not include echocardiography or cardiac MRI as a reference standard. It could be proven in previous studies that ECG-synchronized CT scanning is comparable to magnetic resonance imaging (MRI) in the evaluation of RV and LV function [13]. This also allowed the examination of differential diagnoses for dyspnea, such as cardiac decompensation, etc., in addition to PE confirmation/exclusion.

For the evaluation of right ventricular function, only the ejection fraction was assessed, without paying additional attention to regional wall motion abnormalities, since the aim of this study was simply to prove the feasibility of the proposed CT protocol. Over all patients, RVEF showed no statistically significant difference between PE and non-PE patients. This might be due to the fact that the non-PE group included 12 patients (23.5\%) with preexisting right heart insufficiency.

RV function and the standard value for RVEF depend on age, gender and body surface area [14] and therefore can show significant variability. This also applies to LV function [15]. To rule out these influences, we calculated the ratio of RVEF and LVEF.

Our study has three main limitations, which have to be considered. First, we had a relatively small sample size - which was, however, adequate to assess the feasibility of our CT protocol. Second, we did not correlate CT findings of RV function with transthoracic echocardiography as a gold standard for the assessment of RV function in patients with acute PE. Third, there was no correlation of our results with clinical outcome, since this was merely a feasi- bility study, as already mentioned above. Thus, further studies have to evaluate the additional value of ECG-synchronized measurements with regard to their potential additional benefit in risk stratification and correlation with clinical outcome. It might be of additional value to compare end-systolic and end-diastolic parameters regarding their diagnostic accuracy for determining RVD in patients with acute PE.

\section{CLINICAL RELEVANCE OF THE STUDY}

The novel CT protocol evaluated in this study allows the diagnosis of PE and detailed analysis of RV function at the same time. This might help with respect to rapid risk stratification in patients with acute $\mathrm{PE}$, especially when echocardiography is not directly available. It shows good image quality and an acceptable radiation dose when compared to standard CTPA protocols.

\section{Conflict of Interest}

The authors declare that they have no conflict of interest.

\section{References}

[1] Goldhaber SZ, Visani L, De Rosa M. Acute pulmonary embolism: clinical outcomes in the International Cooperative Pulmonary Embolism Registry (ICOPER). Lancet (London, England) 1999; 353: 1386-1389

[2] Grifoni S, Olivotto I, Cecchini P et al. Short-term clinical outcome of patients with acute pulmonary embolism, normal blood pressure, and echocardiographic right ventricular dysfunction. Circulation 2000; 101: 2817-2822

[3] Goldhaber SZ, Elliott CG. Acute pulmonary embolism: part II: risk stratification, treatment, and prevention. Circulation 2003; 108: 2834-2838 
[4] Konstantinides SV, Torbicki A, Agnelli G et al. 2014 ESC guidelines on the diagnosis and management of acute pulmonary embolism. European heart journal 2014; 35: 3033 - 3069 69a-69k

[5] Goldhaber SZ. Echocardiography in the management of pulmonary embolism. Annals of internal medicine 2002; 136: 691 - 700

[6] Aujesky D, Jimenez D, Mor MK et al. Weekend versus weekday admission and mortality after acute pulmonary embolism. Circulation 2009; 119: $962-968$

[7] Quiroz R, Kucher N, Schoepf UJ et al. Right ventricular enlargement on chest computed tomography: prognostic role in acute pulmonary embolism. Circulation 2004; 109: 2401 - 2404

[8] van der Bijl N, Klok FA, Huisman MV et al. Measurement of right and left ventricular function by ECG-synchronized CT scanning in patients with acute pulmonary embolism: usefulness for predicting short-term outcome. Chest 2011; 140: 1008-1015

[9] Dogan H, Kroft L], Huisman MV et al. Right ventricular function in patients with acute pulmonary embolism: analysis with electrocardiography-synchronized multi-detector row CT. Radiology 2007; 242: 78-84

[10] Bongartz G, Jurik AG, Leonardi M et al. European Guidelines for Multislice Computed Tomography. European Commission. 2004. Appendix C
[11] Goldhaber SZ. Pulmonary embolism. The New England journal of medicine 1998; 339: $93-104$

[12] Takx RA, Schoepf UJ, Moscariello A et al. Coronary CT angiography: comparison of a novel iterative reconstruction with filtered back projection for reconstruction of low-dose CT-Initial experience. Eur J Radiol 2013; 82: $275-280$

[13] Takx RA, Moscariello A, Schoepf UJ et al. Quantification of left and right ventricular function and myocardial mass: comparison of low-radiation dose 2nd generation dual-source CT and cardiac MRI. Eur J Radiol 2012; 81: e598-604

[14] Maceira AM, Prasad SK, Khan M et al. Reference right ventricular systolic and diastolic function normalized to age, gender and body surface area from steady-state free precession cardiovascular magnetic resonance. European heart journal 2006; 27: $2879-2888$

[15] Lei $X$, Liu H, Han Y et al. Reference values of cardiac ventricular structure and function by steady-state free-procession MRI at 3.0T in healthy adult chinese volunteers. Journal of magnetic resonance imaging: JMRI 2017; 45: $1684-1692$ 